\title{
Problems of Female Community Health Volunteers Providing Health Care Service in Nepal
}

\author{
Dr. Deep Bahadur Adhikari \\ Head, Central Department of Education, University campus, Tribhuvan University \\ Kirtipur, Nepal (Email:dip.bdr@gmail.com) \\ DOI: $10.31364 / \mathrm{SCIRJ} / \mathrm{v} 6.18 .2018 . P 0818565$ \\ http://dx.doi.org/10.31364/SCIRJ/v6.i8.2018.P0818565
}

\begin{abstract}
The present research paper was the problems of Female Community Health Volunteers (FCHVs) regarding health care in Nepal. The main objective of this study was to identify health care practice and problems of FCHVs. The descriptive research design was used in this paper. The purposive and census sampling method were applied for this paper. The primary data were collected from 55 FCHVs of Baglung district of Nepal. Result showed more number of the respondents 20 percent belonged on the middle age group (45 to 50 years). Higher proportion of the respondents 78.18 percent were found literate. Similarly, majority of respondents 95.72 percent were trained and few 4.28 percent were untrained. Regarding the knowledge most of the FCHVs 77 percent had knowledge on immunization like, BCG, TT, and measles vaccine, 96.36 percent had knowledge on health check-up during pregnancy and 97 percent of FCHVs were aware from communicable disease. Research showed FCHVs were found involved and contributed in teaching about preparing ORS, importance of breast feeding, regular health checkup and making Sarbottam Pitho. Likewise, they were found involved in immunizing to the children as well as educating about communicable disease and family planning methods. FCHVs are perceived as strong promoters of community health care services as well as social leaders of the community. The FCHV program has undoubtedly contributed towards health promotion through preventive and promoter health services. The FCHV are facing so many problems in their work. They have to walk on foot 1-2 hours for their service one of the respondents reported due to remoteness of the villages. It is very difficult to convince the uneducated people about to use the health service because some of them are motivated to traditional healers. They have no enough materials and physical facilities to perform their work. They are working with voluntarily that is also their main problem because without incentive no one can perform any work effectively.
\end{abstract}

Key words: Female community health volunteers, vaccines, immunization, antenatal, prenatal, postnatal Sabrbottam Pitho, neonatal and morbidity

Introduction

The Female Community Health Volunteer (FCHV) program in Nepal was started by the Ministry of Health and population in 1988. FCHVs are the grassroots level Health service providers who are serving inside the communities. Eighteen days schedule of FCHVs basic training has been provided to the new recruited FCHVs including knowledge of basic health services. These volunteers are devoting their life for the sake of community health without any salary. (Shrestha, 2006). The major role of the FCHV is to promote health and healthy behavior of mothers and community people for the promotion of safe motherhood, child health, family planning and other community based health services with the support of health personnel from sub health post (SHP), Health Post (HP) and Primary Health Care System (PHC) (RHDP, 2007). FCHVs are working specially as key source for Maternal and child 
health care to support the goal of the national safe motherhood program is to reduce maternal and neonatal mortalities by addressing factors related to various morbidities death \& disability caused by complications of pregnancy \& child birth. Global evidence shows that all pregnancies are at risk $\&$ complicated. Delivery $\&$ the post natal period are difficult to predict (Department of Health Services, 2012/13). Study shows that infectious disease maternal prenatal and nutritional health problems continue to lead to half of Nepal's mortality and most disability-adjusted life year (DALY) lost. The loss of DALYs suffered by women of reproductive age (15-49years) is 26 percent higher than that of man and children fewer than five accounts for over 50 percent of all DALYs lost. Additionally; Marginalized people suffer a disproportionate burden of ill health. The National Infant Mortality Rate (IMR) for example is 64 per 1000 but among children it is 166 (Bhatia \& Jha, 2004).

Nepal is an underdeveloped country where the condition of health and education is so weak. Due to the lack of education also affected to health of the people. The same problem is seen in rural VDCs of Baglung district area of this study. FCHVs have to face various challenges while doing their job because people are illiterate. Due to illiteracy, it seems difficult to interact and solve the problems related to health. Also because of challenging geographical condition hospitals and health-post are not easily accessible to people. When patient need to be examined they must walk for at least $4 / 5$ hours on foot to get to the hospital. Due to lack of facility of transportation has made victims to die on the way before they reach the hospital. Other problem is that the people living in this place give more priority to Dhami Jhhakri then modern treatment. Poverty also a problem discourages to motivate the modern treatment. There were lack well facilities \& well equipped materials even to first aid treatment. Because of all these problems patient have to die before they get any immediate health care. Viewing this context this paper tries to high light the problems of the FCHVs to provide maternal and child health care.

\section{Objectives}

The objectives of this study were to explore status, health care practice and problems of FCHVs.

\section{Methods and Procedure}

The design of this research paper was descriptive in quantitative nature. This study was entirely based on primary data. The research areas were the Burtibang, Devisthan and Rajkut Village Development Committees (VDC) of Baglung district of Nepal which were selected purposively. For this research paper, there were taken 55 Female Community Health Volunteers (FCHVs) from those research areas through census method (Best \& Khan, 2002). Interview schedule was used as the tools of data collection. Both closed and open type questions were included in this interview schedule. The data were analyzed using statistical means like, percentage, and ratio. Charts and figures was also be used to make presentation more clear (Kandel, 2005).

\section{Results and Discussion}

The result and discussion of this paper are as follows:

\section{The socio-economic and demographic status of respondents}

This section presents the data on the basis of age group, education, occupation, and type of family of the respondents (Bhusal, 2010).

a. Age of the respondents: Age is a principal factor to determine their knowledge and skills. Government of Nepal has developed the guideline of age limitation of FCHVs, who were over 60 years; they can have their volunteer job by taking ten thousand $(10,000)$ 
rupees as a reward in their long time involvement in the volunteer job at community. Table 1 shows age distribution of the respondents of this study.

Table 1: Age of the respondents

\begin{tabular}{|l|l|l|}
\hline Age group & Number & Percentage \\
\hline $20-29$ & 10 & 18.18 \\
\hline $30-39$ & 13 & 23.46 \\
\hline $40-49$ & 18 & 32.73 \\
\hline 50 and above & 14 & 25.49 \\
\hline Total & 55 & 100.00 \\
\hline
\end{tabular}

According to table no.1 out of total 55 FCHVs they all were between 20 to 60 years. The highest percentage of respondents 32.73 percent were between 40-49 years and lowest number in 20-29 years of age group that is 18.18 percent. It shows about 60 percent of the respondents were above 40 years.

b. Education: Education is the most important factor for all-round development of the nation, without education the human is like blind. The educational status of FCHVs may affect the health care practices they adopt. So in this study educational status of the respondents has been calculated and the result is presented in table no 2 .

Table 2: Educational status of respondents

\begin{tabular}{|l|l|l|}
\hline Level of education & No of respondents & Percentage \\
\hline Illiterate & 12 & 21.82 \\
\hline Literate (Read and write only) & 12 & 21.82 \\
\hline Primary level & 6 & 10.90 \\
\hline Lower secondary level & 10 & 18.18 \\
\hline Secondary level & 9 & 16.36 \\
\hline Higher secondary level & 6 & 10.90 \\
\hline Total & 55 & 100.00 \\
\hline
\end{tabular}

Table 2 shows that illiterate respondents were 21.82 percent whereas literatures were 78.18 percent. Among the respondents who had formal education 10.90 percent had primary level education whereas 18.18 lower secondary, and 16.36 had secondary level education and lowest percent 10.90 in higher secondary level.

c. Occupation: The occupational status of the respondents has revealed that all the respondents were engaged in their own work along with their volunteer work. 


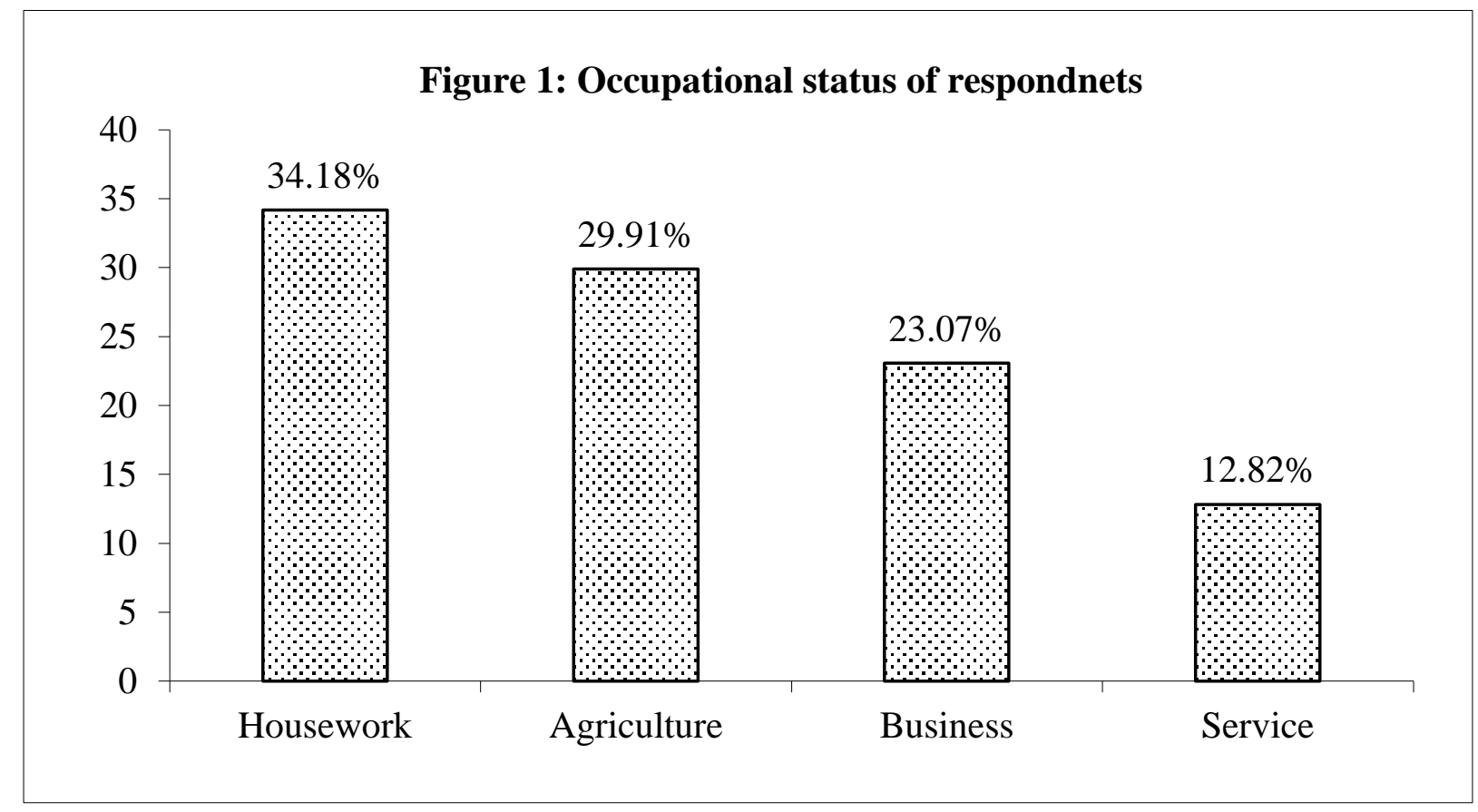

Figure 1 indicates that most of the respondents found engaged in house work and agriculture. Out of 55 respondents the majority 34.18 percent were engaged in house work, 29.91 percent were involved in agriculture, 23.07 percent in business and 12.82 percent found engaged in services. (See fig.11)

d. Type of family: Experiences have been shown that the nuclear families are going to be increased due to industrialization and modernization of societies in the world and nation. The family structure of respondents (FCHVs) of this study is given in table no 3.

Table 3: Type of family on the basis of number

\begin{tabular}{|l|l|l|}
\hline Family & Number & Percentage \\
\hline Nuclear family & 20 & 36.36 \\
\hline Joint family & 35 & 63.64 \\
\hline Total & 55 & 100.00 \\
\hline
\end{tabular}

Table 3 shows the majority of respondents 63.64 percent were from joint family whereas 36.34 percent were in nuclear family. This result shows still more people are living in joint family. The FCHVs who are living in joint family can contribute more time for volunteer work.

\section{Health care practices and problems of FCHVs}


a. Knowledge on time of giving different vaccines to mothers and children: The respondents of the study were also asked to respond about their knowledge on time of giving different vaccines to mothers and children (Buddha, 2011). The data related to this item is presented in the table no 4 .

Table 4: Knowledge of frequency for different vaccines among FCHVs

\begin{tabular}{|l|l|l|}
\hline Name of Vaccines & Yes & No \\
\hline TT & 76.92 & 23.08 \\
\hline BCG & 76.92 & 23.08 \\
\hline DPT & 31.1 & 68.9 \\
\hline Polio & 31.1 & 68.9 \\
\hline Measles & 76.92 & 23.08 \\
\hline Health check up & 96.36 & 3.64 \\
\hline
\end{tabular}

Table no 4 indicates that more than 75 percent of the FCHVs are confirmed about time and frequency of TT, BCG and Measles vaccine. But only one third of the FCHVs are confirmed about the three doses of DPT and Polio Vaccine. The data also has shown that 96.36 percent of the FCHVs have clear knowledge of pregnancy checkup.

b. Knowledge on preparing Oral Rehydration Solution (ORS): Care of the mother and new born baby after delivery is important. The following table no 5 shows their knowledge on preparing ORS:

Table 5: Knowledge on preparing ORS

\begin{tabular}{|l|c|c|l|c|}
\hline \multirow{2}{*}{ Preparing ORS } & \multicolumn{2}{|l|}{ Yes } & No \\
\cline { 2 - 5 } & $\begin{array}{l}\text { Number of } \\
\text { Respondents }\end{array}$ & Percentage & $\begin{array}{l}\text { Number of } \\
\text { Respondents }\end{array}$ & Percentage \\
\hline Educated & 41 & 95.44 & 2 & 4.56 \\
\hline Uneducated & 11 & 91.66 & 1 & 08.33 \\
\hline Total & 52 & 94.54 & 3 & 5.46 \\
\hline
\end{tabular}

The table 5 shows that 94.54 percent respondents were informed about ORS and only 5.46 percent were not found informed. In sum it is indicated that educated FCHVs had slightly more knowledge about preparing ORS in comparison to uneducated ones.

c. The practice of teaching for making "Sarbottan Pitho": "Sabrbottam Pitho" is diet for child fulfilling the need of carbohydrate and protein for children. It is can be made using local materials It is cheaper and healthier diet for children. It should be made properly mixing the different grains. Result shows that out of 55 respondent's majority 85.47 percent had involved to teach making "Sarbottam Pitho" whereas 14.53 percent found not involved. Data further indicates that majority of respondent found involved to teach making "Sarbottam Pitho" but still there is necessity of further educative program for more improvements.

d. Involvement of FCHVs to support in delivery care: In order to find out the number of FCHVs involvement to support delivery care researcher asked a question how many mothers you supported to care delivery in this year. The answer is presented in table no 6 below: 
Table 6: Number of mothers supported to care delivery

\begin{tabular}{|l|ll|l|}
\hline SN & \multicolumn{2}{|l|}{ Number of FCHVs and place } & Number of mothers supported \\
\hline 1. & Burthibang 25 & 53 \\
\hline 2. & Devisthan 20 & 47 \\
\hline 3. & Rajkot & 10 & 25 \\
\hline Total & \multicolumn{2}{|r|}{55} & 125 \\
\hline
\end{tabular}

The table 6 shows that the 53 mothers from Burtibang VDC, 53 mothers from Devisthan and 25 mothers from Rajkot VDC benefited to delivery care this year under the care of FCHVS. In total 125 mothers were supported to care delivery by the FCHVs this year. This indicates important role of FCHVs to care delivery of the mothers.

e. The number of pregnant women in contact for advice: The FCHVs were also asked about the number of pregnant women in contact with the FCHVs for advice this year. The responses are the following table no 7:

Table 7: The number of pregnant women in contact for advice

\begin{tabular}{|l|l|c|c|}
\hline S.N. & \multicolumn{2}{|l|}{ Number of FCHVs } & Number of pregnant women in contact \\
\hline 1. & Burthibang & 25 & 71 \\
\hline 2. & Devisthan & 20 & 54 \\
\hline 3. & Rajkot & 10 & 32 \\
\hline Total & & 55 & 157 \\
\hline
\end{tabular}

The table no 7 shows the number of pregnant women who were in contact with the FCHVs for advice. The data shows that 71 pregnant women were in contact for advice with the FCHVs of Burthibang VDC, 54 pregnant women from Devisthan and 10 were from Rajkot VDC. It shows that the FCHVs provided advice to the 157 pregnant women in total in a year. It is a great contribution.

f. Visiting health institutions: The Female Community Health volunteers should visit health institution heath to provide service at the community level. The given table 8 shows the details of it:

Table 8: Visiting health institutions

\begin{tabular}{|l|l|l|}
\hline Respondents & Number & Percentage \\
\hline One time & 10 & 18.18 \\
\hline Two times & 25 & 45.46 \\
\hline Three times & 12 & 21.81 \\
\hline More than three times & 8 & 14.54 \\
\hline Total & 55 & 100.00 \\
\hline
\end{tabular}

The above table 8 shows that out of 55 FCHVs 18.18 percent visited health institution one time, 45.46 percent two times, 21.81 percent three time and 14.54 percent visited more than three times in a month. That indicates their more work load in spite of their poor benefits. 
g. Major problems faced by respondents: Mainly the role and responsibility of FCHVs are to counsel to the child bearing aged women as well as pregnant and delivered women regarding the appropriate age of marriage, appropriate age of first pregnancy, care during pregnancy and counseling about safe delivery. However, while providing such services, they have been facing various problems. The researcher asked question for FCHVs about the problems thy faced while providing such services. The responses are presented in the figure no 2:

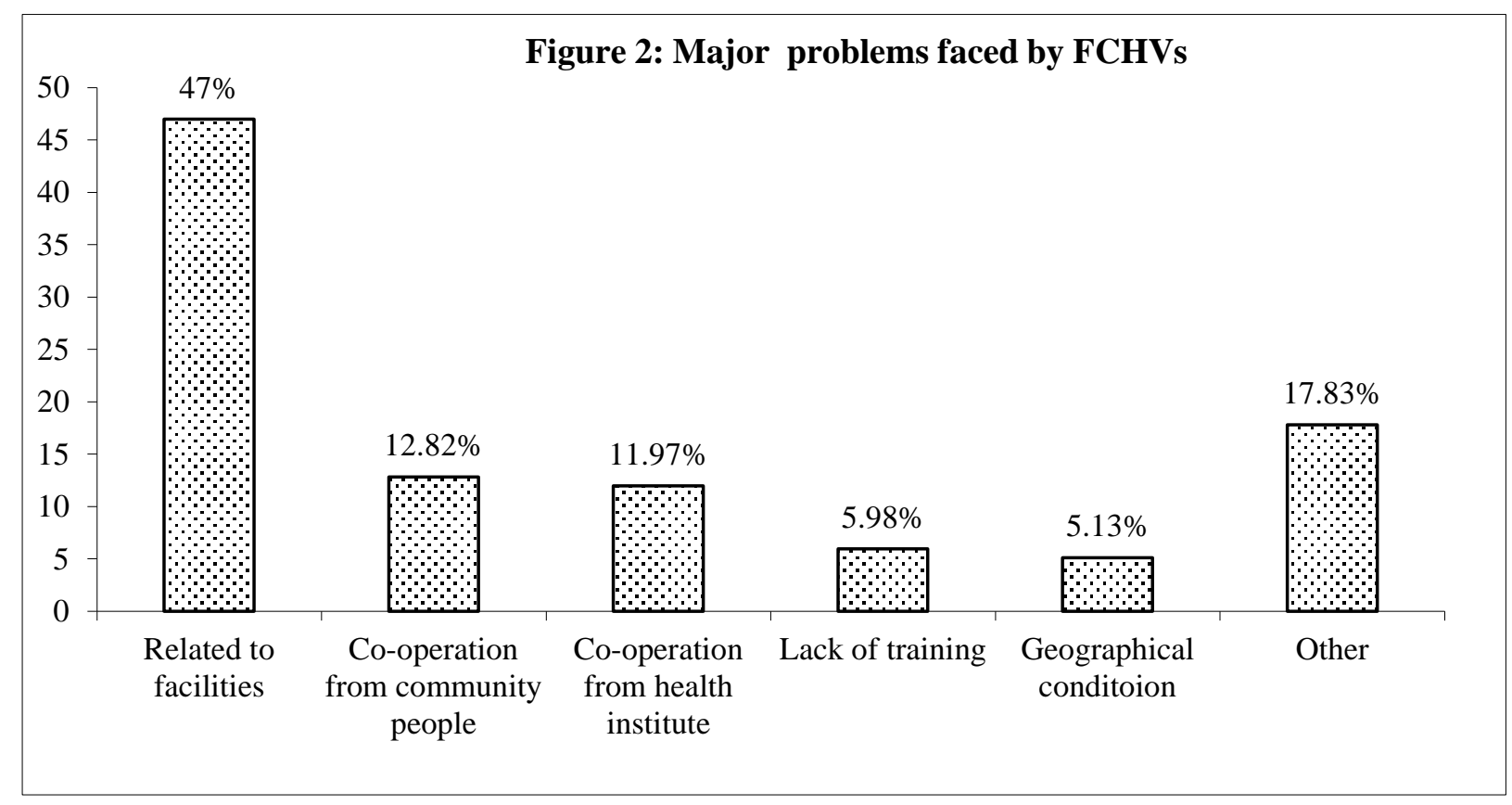

The above figure 2 shows out of 55 FCHVs about 47 percent replied that they faced problems related to facilities, 12.82 percent reported lack of cooperation from the community people and 11.97 percent reported lack of co-operation from health institution. Few percent reported lack of training and geographical barrios as their major problems for working.

\section{Conclusion}

This research paper has been done on the topic of problems of FCHVs providing health care among female community health volunteers of Baglung district of Nepal. FCHVs are the key service provider and have been working since 2045 B.S. in Nepal. They are over whelming by different community based programs in the health sector specially they are responsible for natural care program and expected to have general information about safe motherhood services. Most of the respondents (FCHVs) were literate and they had good knowledge and practice in their various work field. About 96 percent were trained and few 4.25 percent were untrained. However FCHV were not fully aware about safe motherhood services they were working antenatal, prenatal and postnatal care as well as prevention and treatment of illness. Health institutions working in community, social organizations and local people have acknowledged and appreciated the efforts undertaken by FCHVs in health care promotion. Study finding indicated that the majority of respondents 96.36 percent had knowledge on health check-up in during pregnancy period. Educated FCHVs had slightly sound knowledge and practice of maternal and child health and disease as compared to the uneducated ones. Most of the FCHVs had good knowledge on preparing ORS and "Sarbottam Pitho". About 47 percent replied that they faced problems related to facilities while they were volunteering in their community. The most problems were faced by FCHV in their work due to geographical difficulties and lack of transportation facilities they walked on foot 1-2 hours for their work to reach the remote villages. It was very 
difficult to convince the illiterate people about to provide the health service because some of them who were motivated to traditional healers. Due to lack of enough materials and physical facilities it was very difficult to perform their work. From this research paper, it is recommended to provide frequently training, seminar and workshop for FCHVs to increase their performance. FCHVs had not adequate supply of essential commodities therefore health facilities and materials should be made available sufficiently by the administrative side. Likewise, fixed salary even in small amount should be paid to the FCHVs to promote their job efficiency. And also Nepal government should be conducted of direct supervision of FCHVs program in regular basis and suggest and encourage them for better practice.

\section{References}

Best, J. W. \& Khan, J. V. (2002). Research in education. New Delhi: Prentice-Hall of India Private Limited, India.

Bhatia, \& Jha (2004). Gender \& social exclusion assessment (GSEA). Inception workshop April 19, 2004, Kathmandu.

Bhusal, T. (2010). An investigation on female community health volunteers (FCHV) role and impact in health sector of the people in southern villages of Parbat district. An unpublished master thesis submitted to central department of zoology institute of science and technology. T.U., Kirtipur.

Buddha, S. (2011). Utilization of knowledge and skills in providing family planning services by Female community health volunteers in Dang District. An unpublished master's thesis submitted to HPPE Department, T.U., Kirtipur.

Department of health service (2012-2013). Health and population annual report of Nepal. Government of Nepal Ministry of Health and Population. Kathmandu, Nepal.

Kandel, S. (2005). Safe motherhood practice of Mushar community of Pithauli VDC, Nawalparasi. An unpublished master's thesis submitted to HPPE Department, T.U., Kirtipur.

RHDP (2007). FCHV: Rural health development project working experience. Action Research Nepal.

Shrestha, B.K. (2006). Role of female community health volunteer on safe motherhood service in Ramechhap district. An unpublished master's thesis submitted to HPPE Department, T.U., Kirtipur. 